\title{
A Fixed Point Theorem for Multivalued Mappings with $\delta$-Distance
}

\author{
Özlem Acar and Ishak Altun \\ Department of Mathematics, Faculty of Science and Arts, Kirikkale University, Yahsihan, 71450 Kirikkale, Turkey \\ Correspondence should be addressed to Özlem Acar; acarozlem@ymail.com
}

Received 13 June 2014; Accepted 20 July 2014; Published 24 July 2014

Academic Editor: Poom Kumam

Copyright (C) 2014 Ö. Acar and I. Altun. This is an open access article distributed under the Creative Commons Attribution License, which permits unrestricted use, distribution, and reproduction in any medium, provided the original work is properly cited.

We mainly study fixed point theorem for multivalued mappings with $\delta$-distance using Wardowski's technique on complete metric space. Let $(X, d)$ be a metric space and let $B(X)$ be a family of all nonempty bounded subsets of $X$. Define $\delta: B(X) \times B(X) \rightarrow \mathbb{R}$ by $\delta(A, B)=\sup \{d(a, b): a \in A, b \in B\}$. Considering $\delta$-distance, it is proved that if $(X, d)$ is a complete metric space and $T: X \rightarrow$ $B(X)$ is a multivalued certain contraction, then $T$ has a fixed point.

\section{Introduction}

Fixed point theory concern itself with a very basic mathematical setting. It is also well known that one of the fundamental and most useful results in fixed point theory is Banach fixed point theorem. This result has been extended in many directions for single and multivalued cases on a metric space $X$ (see [1-9]). Fixed point theory for multivalued mappings is studied by both Pompeiu-Hausdorff metric $H[10,11]$, which is defined on $C B(X)$ (the family of all nonempty, closed, and bounded subsets of $X$ ), and $\delta$-distance, which is defined on $B(X)$ (the family of all nonempty and bounded subsets of $X$ ). Using Pompeiu-Hausdorff metric, Nadler [12] introduced the concept of multivalued contraction mapping and show that such mapping has a fixed point on complete metric space. Then many authors focused on this direction [13-18]. On the other hand, Fisher [19] obtained different type of multivalued fixed point theorems defining $\delta$-distance between two bounded subsets of a metric space $X$. We can find some results about this way in [20-23].

In this paper, we give some new multivalued fixed point results by considering the $\delta$-distance. For this we use the recent technique, which was given by Wardowski [24]. For the sake of completeness,we will discuss its basic lines. Let $\mathscr{F}$ be the set of all functions $F:(0, \infty) \rightarrow \mathbb{R}$ satisfying the following conditions:
(F1) $F$ is strictly increasing; that is, for all $\alpha, \beta \in(0, \infty)$ such that $\alpha<\beta, F(\alpha)<F(\beta)$.

(F2) For each sequence $\left\{a_{n}\right\}$ of positive numbers $\lim _{n \rightarrow \infty} a_{n}=0$ if and only if $\lim _{n \rightarrow \infty} F\left(a_{n}\right)=-\infty$.

(F3) There exists $k \in(0,1)$ such that $\lim _{\alpha \rightarrow 0^{+}} \alpha^{k} F(\alpha)=0$.

Definition 1 (see [24]). Let $(X, d)$ be a metric space and let $T: X \rightarrow X$ be a mapping. Given $F \in \mathscr{F}$, we say that $T$ is $F$-contraction, if there exists $\tau>0$ such that

$$
\begin{aligned}
& x, y \in X, \\
& d(T x, T y)>0 \Longrightarrow \tau+F(d(T x, T y)) \leq F(d(x, y)) .
\end{aligned}
$$

Taking different functions $F \in \mathscr{F}$ in (1), one gets a variety of $F$-contractions, some of them being already known in the literature. The following examples will certify this assertion.

Example 2 (see [24]). Let $F_{1}:(0, \infty) \rightarrow \mathbb{R}$ be given by the formulae $F_{1}(\alpha)=\ln \alpha$. It is clear that $F_{1} \in \mathscr{F}$. Then each self-mapping $T$ on a metric space $(X, d)$ satisfying (1) is an $F_{1}$-contraction such that

$$
d(T x, T y) \leq e^{-\tau} d(x, y), \quad \forall x, y \in X, T x \neq T y .
$$

It is clear that for $x, y \in X$ such that $T x=T y$ the inequality $d(T x, T y) \leq e^{-\tau} d(x, y)$ also holds. Therefore 
$T$ satisfies Banach contraction with $L=e^{-\tau}$; thus $T$ is a contraction.

Example 3 (see [24]). Let $F_{2}:(0, \infty) \rightarrow \mathbb{R}$ be given by the formulae $F_{2}(\alpha)=\alpha+\ln \alpha$. It is clear that $F_{2} \in \mathscr{F}$. Then each self-mapping $T$ on a metric space $(X, d)$ satisfying $(1)$ is an $F_{2}$-contraction such that

$$
\frac{d(T x, T y)}{d(x, y)} e^{d(T x, T y)-d(x, y)} \leq e^{-\tau}, \quad \forall x, y \in X, T x \neq T y .
$$

We can find some different examples for the function $F$ belonging to $\mathscr{F}$ in [24]. In addition, Wardowski concluded that every $F$-contraction $T$ is a contractive mapping, that is,

$$
d(T x, T y)<d(x, y), \quad \forall x, y \in X, T x \neq T y .
$$

Thus, every $F$-contraction is a continuous mapping.

Also, Wardowski concluded that if $F_{1}, F_{2} \in \mathscr{F}$ with $F_{1}(\alpha) \leq F_{2}(\alpha)$ for all $\alpha>0$ and $G=F_{2}-F_{1}$ is nondecreasing, then every $F_{1}$-contraction $T$ is an $F_{2}$-contraction.

He noted that, for the mappings $F_{1}(\alpha)=\ln \alpha$ and $F_{2}(\alpha)=$ $\alpha+\ln \alpha, F_{1}<F_{2}$ and a mapping $F_{2}-F_{1}$ is strictly increasing. Hence, it was obtained that every Banach contraction satisfies the contractive condition (3). On the other side, [24, Example 2.5] shows that the mapping $T$ is not an $F_{1}$-contraction (Banach contraction) but still is an $F_{2}$-contraction. Thus, the following theorem, which was given by Wardowski, is a proper generalization of Banach Contraction Principle.

Theorem 4 (see $[24])$. Let $(X, d)$ be a complete metric space and let $T: X \rightarrow X$ be an F-contraction. Then $T$ has a unique fixed point in $X$.

Following Wardowski, Minak et al. [25] introduced the concept of Ćirić type generalized $F$-contraction. Let $(X, d)$ be a metric space and let $T: X \rightarrow X$ be a mapping. Given $F \in \mathscr{F}$, we say that $T$ is a Ćirić type generalized $F$-contraction if there exists $\tau>0$ such that

$$
\begin{aligned}
& x, y \in X \\
& d(T x, T y)>0 \Longrightarrow \tau+F(d(T x, T y)) \leq F(m(x, y)),
\end{aligned}
$$

where

$$
\begin{array}{r}
m(x, y)=\max \{d(x, y), d(x, T x), d(y, T y), \\
\left.\frac{1}{2}[d(x, T y)+d(y, T x)]\right\} .
\end{array}
$$

Then the following theorem was given.

Theorem 5. Let $(X, d)$ be a complete metric space and let $T$ : $X \rightarrow X$ be a Cirić type generalized $F$-contraction. If $T$ or $F$ is continuous, then $T$ has a unique fixed point in $X$.

Considering the Pompeiu-Hausdorff metric $H$, both Theorems 4 and 5 were extended to multivalued cases in [26] and [27], respectively ( see also [28, 29]). In this work, we give a fixed point result for multivalued mappings using the $\delta$ distance. First recall some definitions and notations which are used in this paper.

Let $(X, d)$ be a metric space. For $A, B \in B(X)$ we define

$$
\begin{gathered}
\delta(A, B)=\sup \{d(a, b): a \in A, b \in B\}, \\
D(a, B)=\inf \{d(a, b): b \in B\} .
\end{gathered}
$$

If $A=\{a\}$ we write $\delta(A, B)=\delta(a, B)$ and also if $B=\{b\}$, then $\delta(a, B)=d(a, b)$. It is easy to prove that for $A, B, C \in B(X)$

$$
\begin{gathered}
\delta(A, B)=\delta(B, A) \geq 0, \\
\delta(A, B) \leq \delta(A, C)+\delta(C, B), \\
\delta(A, A)=\sup \{d(a, b): a, b \in A\}=\operatorname{diam} A, \\
\delta(A, B)=0, \quad \text { implies that } A=B=\{a\} .
\end{gathered}
$$

If $\left\{A_{n}\right\}$ is a sequence in $B(X)$, we say that $\left\{A_{n}\right\}$ converges to $A \subseteq X$ and write $A_{n} \rightarrow A$ if and only if

(i) $a \in A$ implies that $a_{n} \rightarrow a$ for some sequence $\left\{a_{n}\right\}$ with $a_{n} \in A_{n}$ for $n \in \mathbb{N}$,

(ii) for any $\varepsilon>0, \exists m \in \mathbb{N}$ such that $A_{n} \subseteq A_{\varepsilon}$ for $n>m$, where

$$
A_{\varepsilon}=\{x \in X: d(x, a)<\varepsilon \text { for some } a \in A\} .
$$

Lemma 6 (see [20]). Suppose $\left\{A_{n}\right\}$ and $\left\{B_{n}\right\}$ are sequences in $B(X)$ and $(X, d)$ is a complete metric space. If $A_{n} \rightarrow A \in B(X)$ and $B_{n} \rightarrow B \in B(X)$ then $\delta\left(A_{n}, B_{n}\right) \rightarrow \delta(A, B)$.

Lemma 7 (see [20]). If $\left\{A_{n}\right\}$ is a sequence of nonempty bounded subsets in the complete metric space $(X, d)$ and if $\delta\left(A_{n}, y\right) \rightarrow 0$ for some $y \in X$, then $A_{n} \rightarrow\{y\}$.

\section{Main Result}

In this section, we prove a fixed point theorem for multivalued mappings with $\delta$-distance and give an illustrative example.

Definition 8 . Let $(X, d)$ be a metric space and let $T: X \rightarrow$ $B(X)$ be a mapping. Then $T$ is said to be a generalized multivalued $F$-contraction if $F \in \mathscr{F}$ and there exists $\tau>0$ such that

$$
\tau+F(\delta(T x, T y)) \leq F(M(x, y)),
$$

for all $x, y \in X$ with $\min \{\delta(T x, T y), d(x, y)\}>0$, where

$$
\begin{array}{r}
M(x, y)=\max \{d(x, y), D(x, T x), D(y, T y), \\
\left.\frac{1}{2}[D(x, T y)+D(y, T x)]\right\} .
\end{array}
$$

Theorem 9. Let $(X, d)$ be a complete metric space and let $T$ : $X \rightarrow B(X)$ be a multivalued $F$-contraction. If $F$ is continuous and $T x$ is closed for all $x \in X$, then $T$ has a fixed point in $X$. 
Proof. Let $x_{0} \in X$ be an arbitrary point and define a sequence $\left\{x_{n}\right\}$ in $X$ as $x_{n+1} \in T x_{n}$ for all $n \geq 0$. If there exists $n_{0} \in \mathbb{N} \cup\{0\}$ for which $x_{n_{0}}=x_{n_{0}+1}$, then $x_{n_{0}}$ is a fixed point of $T$ and so the proof is completed. Thus, suppose that, for every $n \in \mathbb{N} \cup\{0\}$, $x_{n} \neq x_{n+1}$. So $d\left(x_{n}, x_{n+1}\right)>0$ and $\delta\left(T x_{n-1}, T x_{n}\right)>0$ for all $n \in \mathbb{N}$. Then, we have from (10)

$$
\begin{aligned}
& \tau+F\left(d\left(x_{n}, x_{n+1}\right)\right) \\
& \leq \tau+F\left(\delta\left(T x_{n-1}, T x_{n}\right)\right) \\
& \leq F\left(M\left(x_{n-1}, x_{n}\right)\right) \\
& =F\left(\max \left\{\begin{array}{c}
d\left(x_{n-1}, x_{n}\right), D\left(x_{n-1}, T x_{n-1}\right), D\left(x_{n}, T x_{n}\right), \\
\frac{1}{2}\left[D\left(x_{n-1}, T x_{n}\right)+D\left(x_{n}, T x_{n-1}\right)\right]
\end{array}\right\}\right) \\
& \leq F\left(\max \left\{d\left(x_{n-1}, x_{n}\right), d\left(x_{n}, x_{n+1}\right)\right\}\right) \\
& =F\left(d\left(x_{n-1}, x_{n}\right)\right),
\end{aligned}
$$

and so

$$
\begin{aligned}
F\left(d\left(x_{n}, x_{n+1}\right)\right) & \leq F\left(d\left(x_{n-1}, x_{n}\right)\right)-\tau \\
& \leq F\left(d\left(x_{n-2}, x_{n-1}\right)\right)-2 \tau \\
& \vdots \\
& \leq F\left(d\left(x_{0}, x_{1}\right)\right)-n \tau .
\end{aligned}
$$

Denote $a_{n}=d\left(x_{n}, x_{n+1}\right)$, for $n=0,1,2, \ldots$ Then, $a_{n}>0$ for all $n$ and, using (10), the following holds:

$$
F\left(a_{n}\right) \leq F\left(a_{n-1}\right)-\tau \leq F\left(a_{n-2}\right)-2 \tau \leq \cdots \leq F\left(a_{0}\right)-n \tau .
$$

From (14), we get $\lim _{n \rightarrow \infty} F\left(a_{n}\right)=-\infty$. Thus, from (F2), we have

$$
\lim _{n \rightarrow \infty} a_{n}=0
$$

From (F3) there exists $k \in(0,1)$ such that

$$
\lim _{n \rightarrow \infty} a_{n}^{k} F\left(a_{n}\right)=0
$$

By (14), the following holds for all $n \in \mathbb{N}$ :

$$
a_{n}^{k} F\left(a_{n}\right)-a_{n}^{k} F\left(a_{0}\right) \leq-a_{n}^{k} n \tau \leq 0 .
$$

Letting $n \rightarrow \infty$ in (17), we obtain that

$$
\lim _{n \rightarrow \infty} n a_{n}^{k}=0
$$

From (18), there exits $n_{1} \in \mathbb{N}$ such that $n a_{n}^{k} \leq 1$ for all $n \geq n_{1}$. So we have

$$
a_{n} \leq \frac{1}{n^{1 / k}}
$$

for all $n \geq n_{1}$. In order to show that $\left\{x_{n}\right\}$ is a Cauchy sequence consider $m, n \in \mathbb{N}$ such that $m>n \geq n_{1}$. Using the triangular inequality for the metric and from (19), we have

$$
\begin{aligned}
& d\left(x_{n}, x_{m}\right) \\
& \quad \leq d\left(x_{n}, x_{n+1}\right)+d\left(x_{n+1}, x_{n+2}\right)+\cdots+d\left(x_{m-1}, x_{m}\right) \\
& =a_{n}+a_{n+1}+\cdots+a_{m-1} \\
& \quad=\sum_{i=n}^{m-1} a_{i} \\
& \leq \sum_{i=n}^{\infty} a_{i} \\
& \leq \sum_{i=n}^{\infty} \frac{1}{i^{1 / k}} .
\end{aligned}
$$

By the convergence of the series $\sum_{i=1}^{\infty}\left(1 / i^{1 / k}\right)$, we get $d\left(x_{n}, x_{m}\right) \rightarrow 0$ as $n \rightarrow \infty$. This yields that $\left\{x_{n}\right\}$ is a Cauchy sequence in $(X, d)$. Since $(X, d)$ is a complete metric space, the sequence $\left\{x_{n}\right\}$ converges to some point $z \in X$; that is, $\lim _{n \rightarrow \infty} x_{n}=z$. Now, suppose $F$ is continuous. In this case, we claim that $z \in T z$. Assume the contrary; that is, $z \notin T z$. In this case, there exist an $n_{0} \in \mathbb{N}$ and a subsequence $\left\{x_{n_{k}}\right\}$ of $\left\{x_{n}\right\}$ such that $D\left(x_{n_{k}+1}, T z\right)>0$ for all $n_{k} \geq n_{0}$. (Otherwise, there exists $n_{1} \in \mathbb{N}$ such that $x_{n} \in T z$ for all $n \geq n_{1}$, which implies that $z \in T z$. This is a contradiction, since $z \notin T z$.) Since $D\left(x_{n_{k}+1}, T z\right)>0$ for all $n_{k} \geq n_{0}$, then we have

$$
\begin{aligned}
\tau+ & F\left(D\left(x_{n_{k}+1}, T z\right)\right) \\
& \leq \tau+F\left(\delta\left(T x_{n_{k}}, T z\right)\right) \\
& \leq F\left(M\left(x_{n_{k}}, z\right)\right) \\
& \leq F\left(\operatorname { m a x } \left\{d\left(x_{n_{k}}, z\right), d\left(x_{n_{k}}, x_{n_{k}+1}\right), D(z, T z),\right.\right. \\
& \left.\left.\frac{1}{2}\left[D\left(x_{n_{k}}, T z\right)+d\left(z, x_{n_{k}+1}\right)\right]\right\}\right) .
\end{aligned}
$$

Taking the limit $k \rightarrow \infty$ and using the continuity of $F$, we have $\tau+F(D(z, T z)) \leq F(D(z, T z))$, which is a contradiction. Thus, we get $z \in \overline{T z}=T z$. This completes the proof.

Example 10. Let $X=\{0,1,2,3, \ldots\}$ and $d(x, y)=\left\{\begin{array}{cc}0 ; & x=y \\ x+y ; & x \neq y\end{array}\right.$. Then $(X, d)$ is a complete metric space. Define $T: X \rightarrow B(X)$ by

$$
T x= \begin{cases}\{0\} ; & x=0 \\ \{0,1,2,3, \ldots, x-1\} ; & x \neq 0 .\end{cases}
$$

We claim that $T$ is multivalued $F$-contraction with respect to $F(\alpha)=\alpha+\ln \alpha$ and $\tau=1$. Because of the $\min \{\delta(T x, T y)$, 
$d(x, y)\}>0$, we can consider the following cases while $x \neq y$ and $\{x, y\} \cap\{0,1\}$ is empty or singleton.

Case 1 . For $y=0$ and $x>1$, we have

$$
\begin{aligned}
\frac{\delta(T x, T y)}{M(x, y)} e^{\delta(T x, T y)-M(x, y)} & =\frac{x-1}{x} e^{x-1-x} \\
& =\frac{x-1}{x} e^{-1}<e^{-1}
\end{aligned}
$$

Case 2. For $y=1$ and $x>1$, we have

$$
\begin{aligned}
\frac{\delta(T x, T y)}{M(x, y)} e^{\delta(T x, T y)-M(x, y)} & =\frac{x-1}{x} e^{x-1-x} \\
& =\frac{x-1}{x} e^{-1}<e^{-1} .
\end{aligned}
$$

Case 3. For $x>y>1$, we have

$$
\begin{aligned}
\frac{\delta(T x, T y)}{M(x, y)} e^{\delta(T x, T y)-M(x, y)} & =\frac{x+y-2}{x+y} e^{x+y-2-x-y} \\
& =\frac{x+y-2}{x+y} e^{-2}<e^{-1}
\end{aligned}
$$

This shows that $T$ is multivalued $F$-contraction; therefore, all conditions of theorem are satisfied and so $T$ has a fixed point in $X$.

On the other hand, for $y=0$ and $x \neq 0$, since $\delta(T x, T y)=$ $x-1$ and $d(x, y)=x$, we get

$$
\lim _{n \rightarrow \infty} \frac{\delta(T x, T y)}{M(x, y)}=\lim _{n \rightarrow \infty} \frac{x-1}{x}=1
$$

then $T$ does not satisfy

$$
\delta(T x, T y) \leq \lambda M(x, y),
$$

for $\lambda \in[0,1)$.

\section{Conflict of Interests}

The authors declare that there is no conflict of interests regarding the publication of this paper.

\section{Acknowledgment}

The authors are grateful to the referees because their suggestions contributed to improving the paper.

\section{References}

[1] M. U. Ali, T. Kamran, W. Sintunavarat, and P. Katchang, "Mizoguchi-Takahashi's fixed point theorem with $\alpha, \eta$ functions," Abstract and Applied Analysis, vol. 2013, Article ID 418798, 4 pages, 2013.

[2] S. Chauhan, M. Imdad, C. Vetro, and W. Sintunavarat, "Hybrid coincidence and common fixed point theorems in Menger probabilistic metric spaces under a strict contractive condition with an application," Applied Mathematics and Computation, vol. 239, pp. 422-433, 2014.
[3] M. A. Kutbi and W. Sintunavarat, "The existence of fixed point theorems via $w$-distance and $\alpha$-admissible mappings and applications," Abstract and Applied Analysis, vol. 2013, Article ID 165434, 8 pages, 2013.

[4] W. Sintunavarat and P. Kumam, "Coincidence and common fixed points for hybrid strict contractions without the weakly commuting condition," Applied Mathematics Letters, vol. 22, no. 12, pp. 1877-1881, 2009.

[5] W. Sintunavarat and P. Kumam, "Gregus type fixed points for a tangential multi-valued mappings satisfying contractive conditions of integral type," Journal of Inequalities and Applications, vol. 2011, article 3, 12 pages, 2011.

[6] W. Sintunavarat and P. Kumam, "Weak condition for generalized multi-valued $(f, \alpha, \beta)$-weak contraction mappings," Applied Mathematics Letters, vol. 24, no. 4, pp. 460-465, 2011.

[7] W. Sintunavarat and P. Kumam, "Common fixed point theorem for hybrid generalized multi-valued contraction mappings," Applied Mathematics Letters, vol. 25, no. 1, pp. 52-57, 2012.

[8] W. Sintunavarat and P. Kumam, "Common fixed point theorem for cyclic generalized multi-valued contraction mappings," Applied Mathematics Letters, vol. 25, no. 11, pp. 1849-1855, 2012.

[9] W. Sintunavarat, S. Plubtieng, and P. Katchang, "Fixed point result and applications on $b$-metric space endowed with an arbitrary binary relation," Fixed Point Theory and Applications, vol. 2013, article 296, 2013.

[10] R. P. Agarwal, D. O'Regan, and D. R. Sahu, Fixed Point Theory for Lipschitzian-type Mappings with Applications, Springer, New York, NY, USA, 2009.

[11] V. Berinde and M. Păcurar, "The role of the Pompeiu-Hausdorff metric in fixed point theory," Creative Mathematics and Informatics, vol. 22, no. 2, pp. 35-42, 2013.

[12] S. B. Nadler, "Multi-valued contraction mappings," Pacific Journal of Mathematics, vol. 30, pp. 475-488, 1969.

[13] M. Berinde and V. Berinde, "On a general class of multi-valued weakly Picard mappings," Journal of Mathematical Analysis and Applications, vol. 326, no. 2, pp. 772-782, 2007.

[14] L. Ćirić, "Multi-valued nonlinear contraction mappings," Nonlinear Analysis, vol. 71, no. 7-8, pp. 2716-2723, 2009.

[15] N. Mizoguchi and W. Takahashi, "Fixed point theorems for multivalued mappings on complete metric spaces," Journal of Mathematical Analysis and Applications, vol. 141, no. 1, pp. 177188, 1989.

[16] S. Reich, "Fixed points of contractive functions," Bollettino della Unione Matematica Italiana, vol. 5, pp. 26-42, 1972.

[17] S. Reich, "Some fixed point problems," Atti della Accademia Nazionale dei Lincei, vol. 57, no. 3-4, pp. 194-198, 1974.

[18] T. Suzuki, "Mizoguchi-Takahashi's fixed point theorem is a real generalization of Nadler's," Journal of Mathematical Analysis and Applications, vol. 340, no. 1, pp. 752-755, 2008.

[19] B. Fisher, "Set-valued mappings on metric spaces," Fundamenta Mathematicae, vol. 112, no. 2, pp. 141-145, 1981.

[20] I. Altun, "Fixed point theorems for generalized $\varphi$-weak contractive multivalued maps on metric and ordered metric spaces," Arabian Journal for Science and Engineering, vol. 36, no. 8, pp. 1471-1483, 2011.

[21] B. Fisher, "Common fixed points of mappings and set-valued mappings," Rostocker Mathematisches Kolloquium, no. 18, pp. 69-77, 1981.

[22] B. Fisher, "Fixed points for set-valued mappings on metric spaces," Bulletin: Malaysian Mathematical Society, vol. 2, no. 4, pp. 95-99, 1981. 
[23] B. Fisher, "Common fixed points of set-valued mappings," Punjab University Journal of Mathematics, vol. 14-15, pp. 155163, 1981-1982.

[24] D. Wardowski, "Fixed points of a new type of contractive mappings in complete metric spaces," Fixed Point Theory and Applications, vol. 2012, article 94, 2012.

[25] G. Minak, A. Helvac, and I. Altun, "C'iric' type generalized Fcontractions on complete metric spaces and fixed point results," Filomat. In press.

[26] I. Altun, G. Minak, and H. Dağ, "Multivalued F-contractions on complete metric space," Journal of Nonlinear and Convex Analysis. In press.

[27] Ö. Acar, G. Durmaz, and G. Minak, "Generalized multivalued F-contractions on complete metric spaces," Bulletin of the Iranian Mathematical Society. In press.

[28] I. Altun, G. Durmaz, G. Minak, and S. Romaguera, "Multivalued almost $F$-contractions on complete metric spaces," Filomat. In press.

[29] M. Olgun, G. Minak, and I. Altun, "A new approach to Mizoguchi-Takahashi type fixed point theorem," Journal of Nonlinear and Convex Anslysis. In press. 


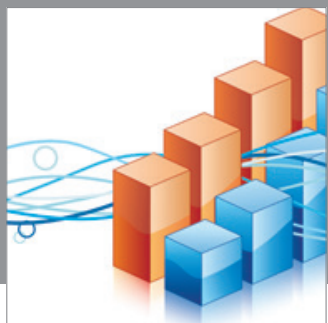

Advances in

Operations Research

mansans

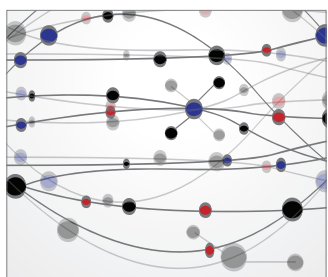

The Scientific World Journal
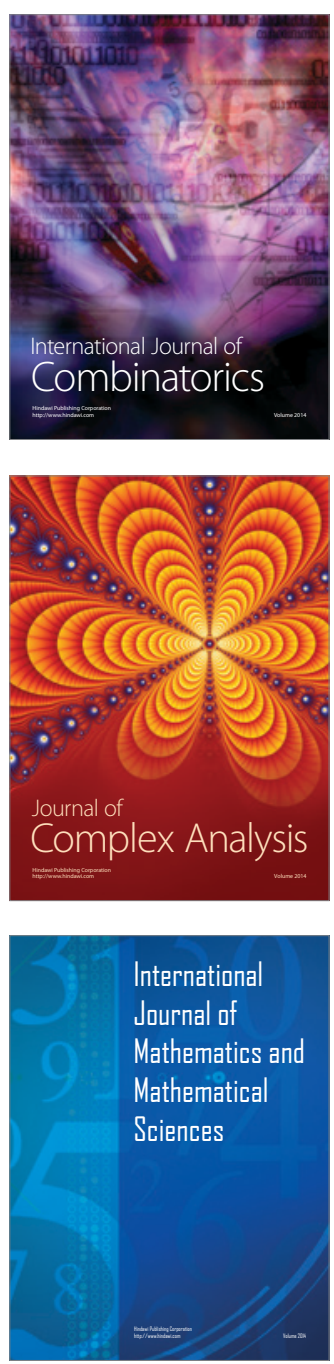
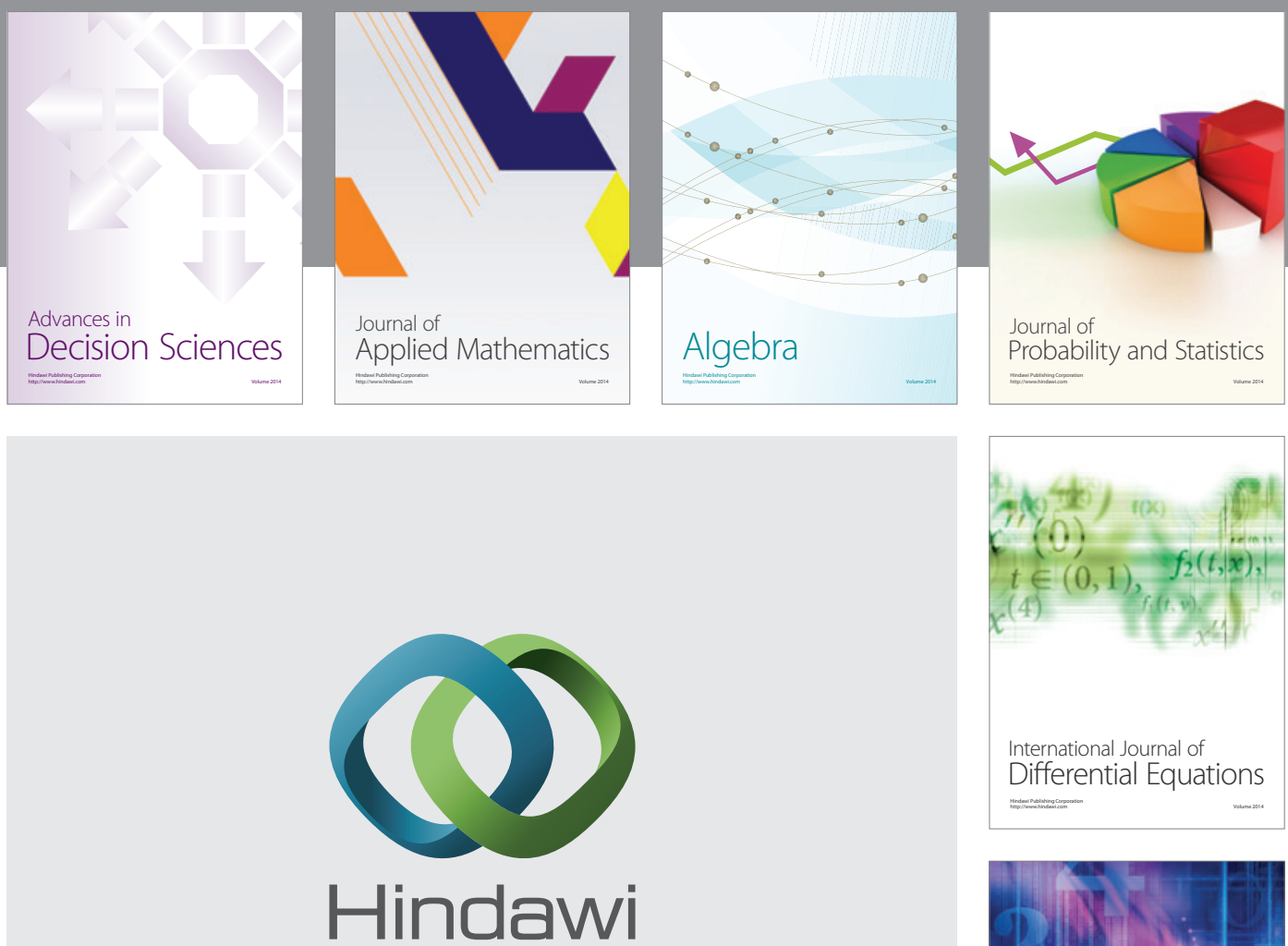

Submit your manuscripts at http://www.hindawi.com
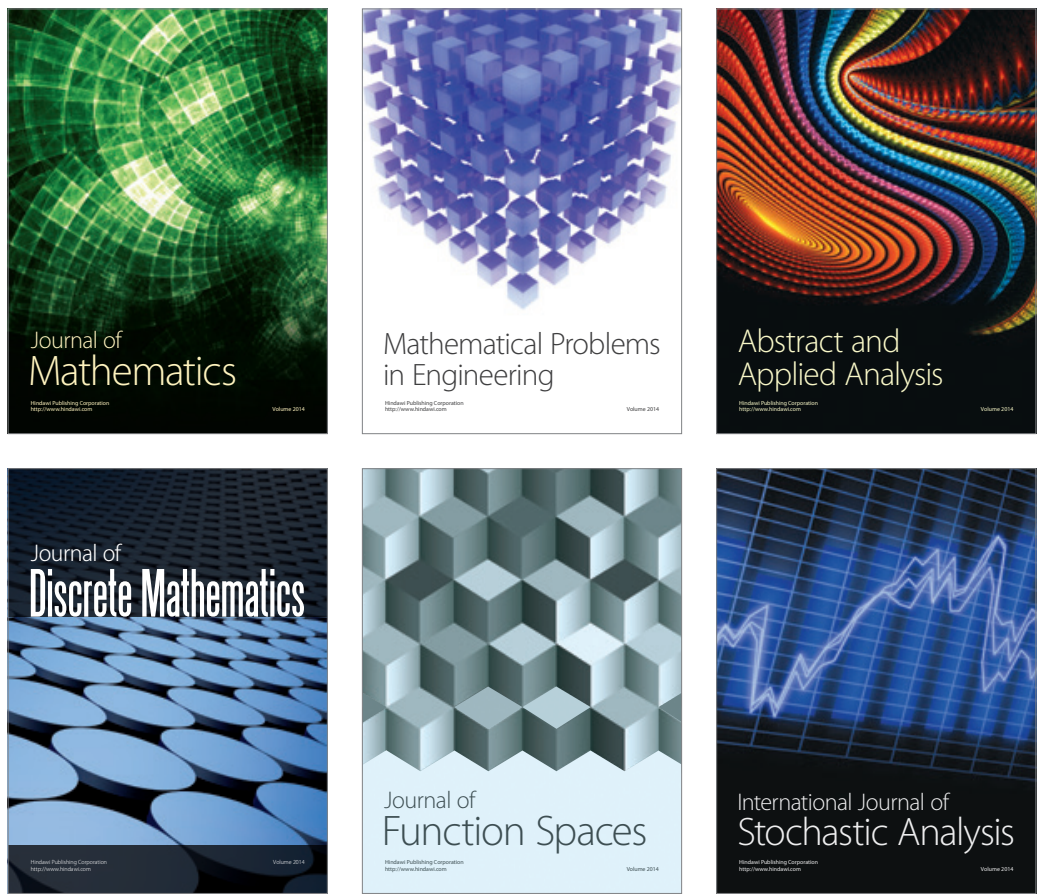

Journal of

Function Spaces

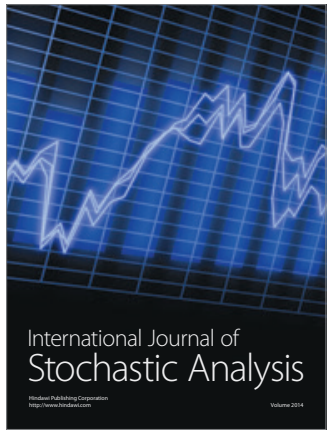

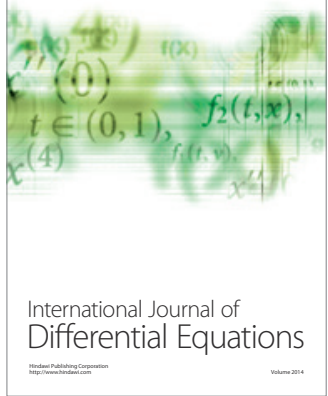
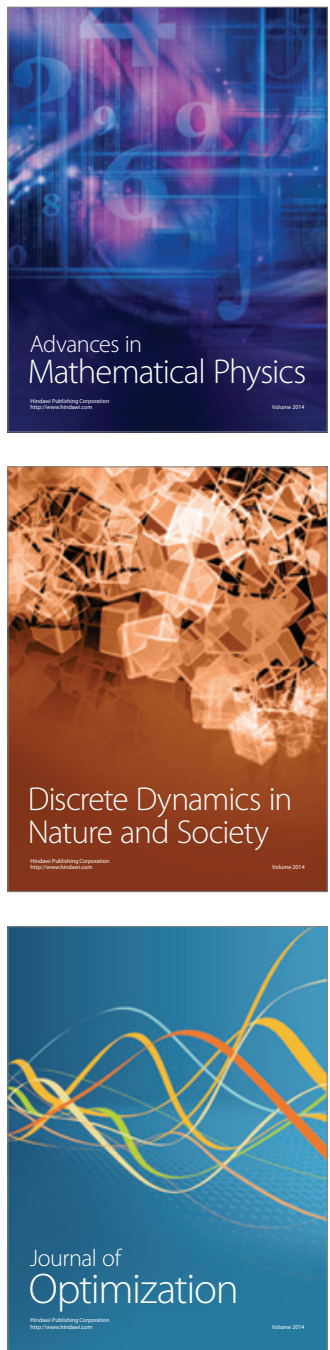